
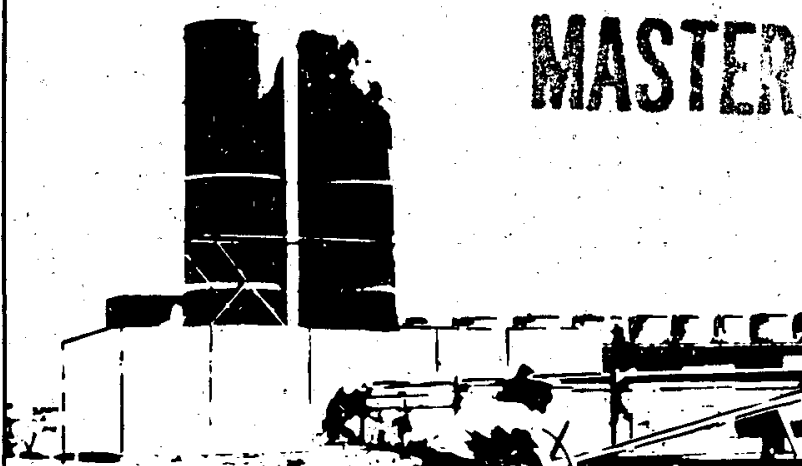

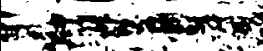
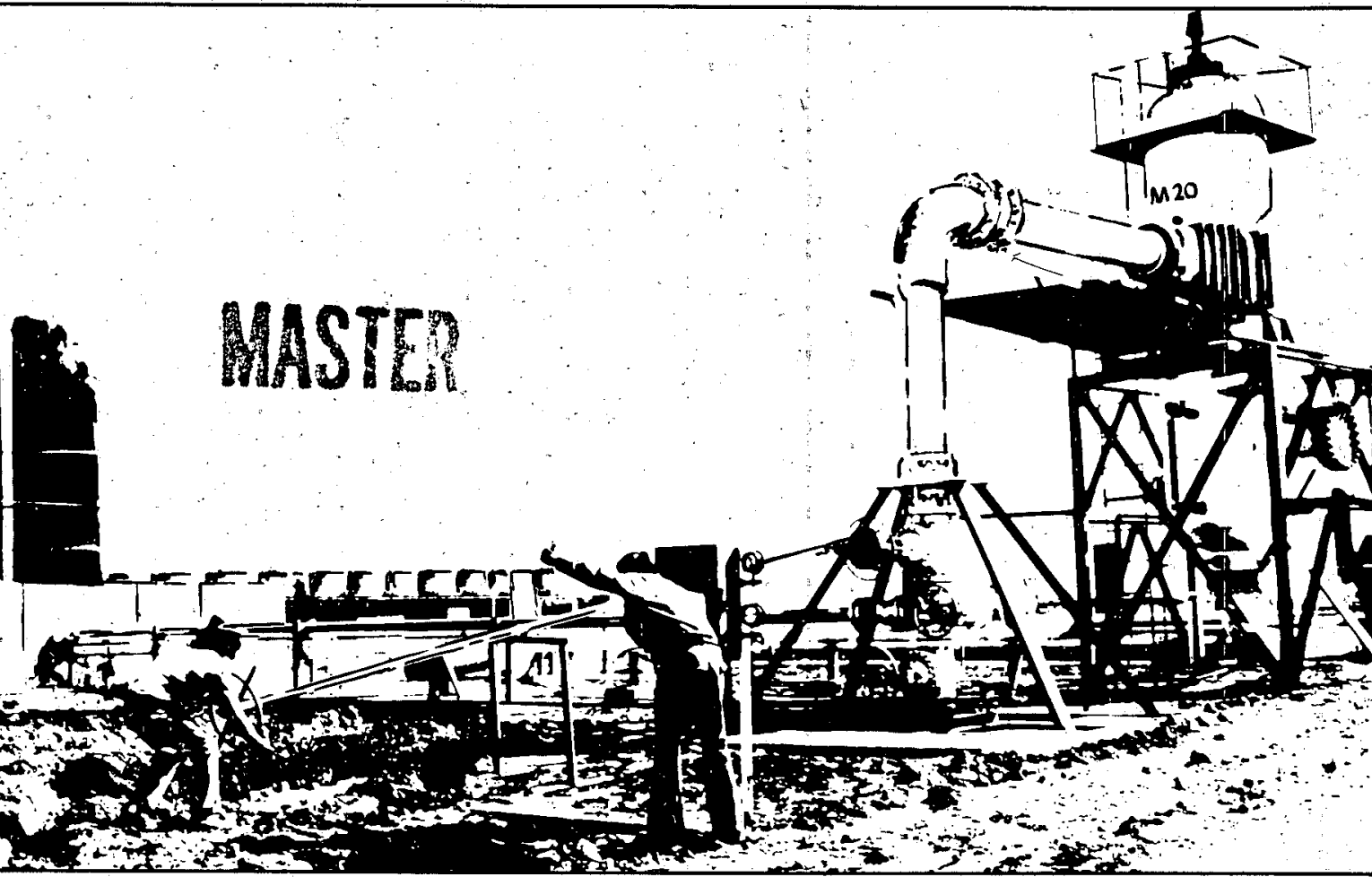

\title{
RESISTIVITY MONITORING AT CERRO PRIETO
}

\author{
Michael J. Wilt and Norman E. Goldstein
}

\author{
FEBRUARY 1980
}

A Joint Project of

COMISION FEDERAL DE ELECTRICIDAD Mexico

DEPARTMENT OF ENERGY

Division of Geothermal Energy

United States of America

Coordinated by

Coordinadora Ejecutiva

de Cerro Prieto

Apdo. Postal No. 3-636

Mexicali, Bja. Cfa., México

and P. O. Box 248

Calexico, Ca. 92231
Lawrence Berkeley Laboratory

Earth Sciences Division

University of California

Berkeley, California 94720

Operating for the U.S. Department of

Energy: under Contract W-7405-ENG-48: 


\section{DISCLAIMER}

This report was prepared as an account of work sponsored by an agency of the United States Government. Neither the United States Government nor any agency Thereof, nor any of their employees, makes any warranty, express or implied, or assumes any legal liability or responsibility for the accuracy, completeness, or usefulness of any information, apparatus, product, or process disclosed, or represents that its use would not infringe privately owned rights. Reference herein to any specific commercial product, process, or service by trade name, trademark, manufacturer, or otherwise does not necessarily constitute or imply its endorsement, recommendation, or favoring by the United States Government or any agency thereof. The views and opinions of authors expressed herein do not necessarily state or reflect those of the United States Government or any agency thereof. 


\section{DISCLAIMER}

Portions of this document may be illegible in electronic image products. Images are produced from the best available original document. 


\section{LEGAL NOTICE}

This report was prepared as an account of work sponsored by the United States Government. Neither the United States nor the Department of Energy, nor any of their employees, nor any of their contractors, subcontractors, or their employees, makes any warranty, express or implied, or assumes any legal liability or responsibility for the accuracy, completeness or usefulness of any information, apparatus, product or process disclosed, or represents that its use would not infringe privately owned rights. 
Submitted to the Proceedings of the Second

Symposium on the Cerro Prieto Geothermal Field,

Baja California, Mexico, October 17-19, 1979

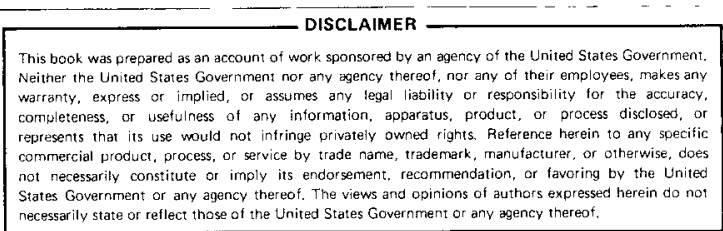

RESISTIVITY MONITORING AT CERRO PRIETO

Michael J. Wilt and Norman E. Goldstein

Lawrence Berkeley Laboratory

University of California

Berkeley, California 94720 


\section{RESISTIVITY MONITORING AT CERRO PRIETO}

Michael J. Wilt and Norman E. Goldstein University of California

Lawrence Berkeley Laboratory Berkeley, California 94720

\section{ABSTRACT}

In 1978 Lawrence Berkeley Laboratory, in cooperation with Comisión Federal de Electricidad, began a program of dipole-dipole resistivity monitoring at the Cerro Prleto geothermal field. Dipole-dipole measurements were first made in 1978, then repeated in 1979: (a) to determine whether the field boundaries could be defined by surface resistivity measurements; and (b) to determine if changes in reservoir conditions due to production may be monitored by surface measurements.

In 1979 data accuracy was Improved to where estimated measurement errors were less than $3 \%$. In addition, data coverage on a line over the field was expanded by $40 \%$ for greater depth of Investigation and more information on the newer, eastern part of the field. Resistivity modeling of the expanded 1979 profile indicates that the resistive body associated with the zone of production (W11t et al., 1978) dips steeply eastward, and may underlie the eastern part of the field. The model also shows a thin steeply dipping conductor adjacent to the resistive body that may be associated with faulting and fluid movement. Model perturbation studies have shown that small changes associated with coldwater influx, fault zone migrations, and formation of a steam zone would all be detectable with preciston dipole-dipole measurements. Telluric profile measurements taken along Iine E- $E^{\prime}$ were found to yfeld a significant amount of reconnalssance Information but are unsultable for monitoring purposes.

\section{INTRODUCTION}

In 1978 Lawrence Berkeley Laboratory, in cooperation with Comision Federal de Electricldad, began a program of dipole-dipole resistivity atudies at the Cerro Prleto geothermal fleld. For collecting geophysical data, two east-west survey lines were established; one (E- $\left.E^{\prime}\right)$ crossing the central part of the production area near the power plant, and the other $\left(D-D^{\prime}\right)$ about $4 \mathrm{~km}$ north of the plant, passing imnedlately south of the Cerro Prieto volcano (F1g. 1). Dipole-dipole resistivity measurements were then conducted in 1978 and 1979. The utmost care was taken to achieve the best accuracy obtainable with the available instrumentation.

The goals of this profect are to construct a resistivity model of the Cerro Prleto region consistent with known geology, and to determine if changes in reservolr conditions due to production (e.g. formation of a vapor zone,

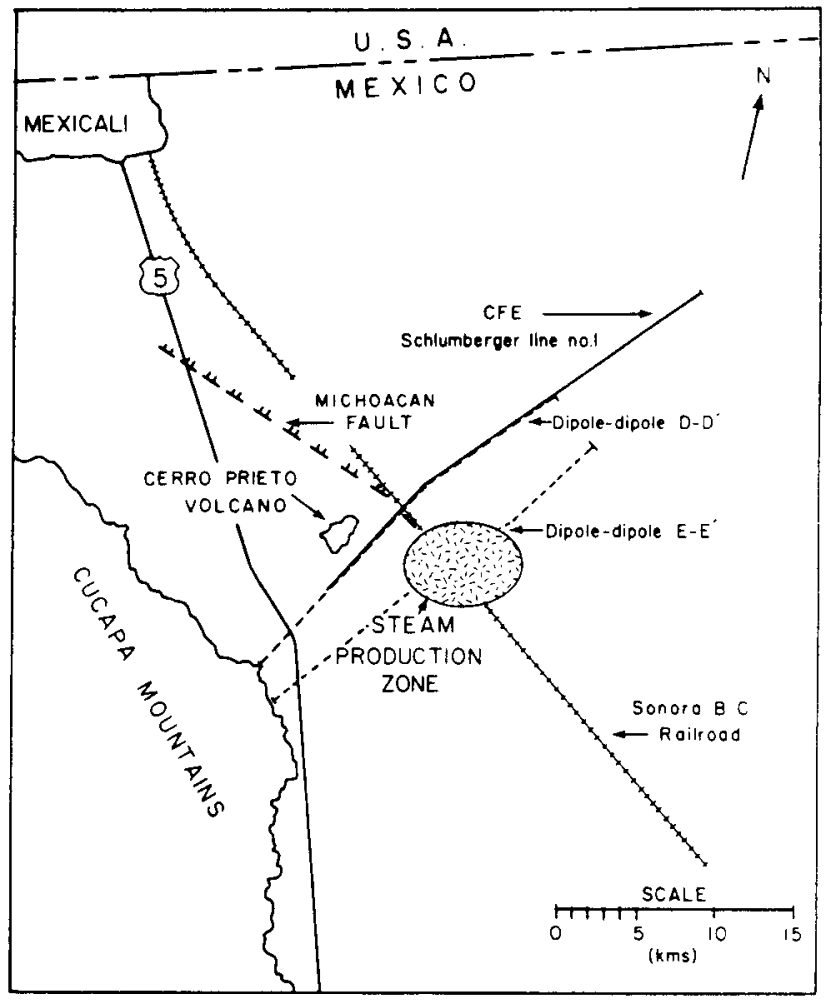

XBL 788-1632

Figure 1. Project location map, LBL resistivity project.

changes in porosity at the periphery of the reservoir) may be monitored by means of accurate surface resistivity measurements.

Results of the 1978 survey were presented In an earlier paper (Wilt et al., 1979); a summary of the significant findings is given below.

1. The production region at Cerro Prieto 1s characterized by a resistivity high relative to the surrounding rocks. Average formation resistivities are $2.0 \mathrm{ohm}-\mathrm{m}$ or less, increasing to at least $4.0 \mathrm{ohm}-\mathrm{m}$ with in the zone. Analyses of well $\log s$ and drill cuttings (Elders and Hoagland, 1979) suggest that the increase is primarily due to the formation of reduced porosity zones caused by hydrothermal metamorph1sm within the reservoir region. 
2. Modeling studies showed that resistivity variations with time are theoretically detectable by means of surface dipole-dipole measurements. However, the degree of accuracy needed to observe such variations must be greater than $5 \%$; a better accuracy than we could achleve at large electrode spacings in 1978 .

\section{PROGRESS IN 1979}

In 1979 line $E-E^{\prime}$ was remeasured with $1-\mathrm{km}$ dipoles but with significantly greater accuracy than in 1978, providing better modeling constraints and establishing a reliable baseline for future observations of resistivity changes. The LBL 25-kW motor generator was used as the power source in both years, but greater accuracy was achieved in 1979 because of superior recelver instrumentation, mechanical improvements to the power source, and the experience gained from the prevlous year. New signal-averaging recelvers were used to average 10 cycles of the $40-8 e c-$ period square-wave pulse supplied to the ground by the transmitter. At each point of measurement a minimum of 70 cycles were averaged and the mean and standard deviations were computed. The $40-s e c$ period was selected as the best compromise for speed of survey and avoldance of electromagnetic coupling effects. Improvements to the transmitter in 1979--namely a reconditioned engine, new cable, and lower contact resistance at electrodes--allowed us to inject up to $40 \mathrm{~A}$ compared with 15 to $25 \mathrm{~A}$ in 1978.

In 1979 dipole-dipole measurements were extended $4 \mathrm{~km}$ farther eastward and the maximum transmitter recelver separations were increased from $N=6$ to $N=8$, thereby ylelding a greater depth of exploration. In addition telluric profile measurements were made along line E-E* to test the applicability of this relatively fast and Inexpensive method for resolving subsurface structure.

Following data acquisition, the expanded and more accurate results were used to develop an improved two-dimensional resistivity crosssection for Iine E-E' (Figs, 2 and 3). New model perturbation studies were performed to 1dentify points of maximum 11kely interest, such as points where reservolr changes might be most easily recognized, and to examine the magnitude of resistivity change for several possible reservolr changes. An analysis of measurement errors was done wh the 1978 and 1979 data and the two sets were compared to see if (a) new measurements (1979) fall within the predicted errors and (b) if data accuracy is sufficient to isolate any changes in reservolr conditions.

Telluric data taken in 1979 were analyzed, and errors were evaluated to determine if $1 \mathrm{t}$ is possible to use this method for resistivity monitoring.

\section{DIPOLE-DIPOLE RESULTS}

Dpole-dipole apparent resistivity data taken In 1979 and the accompanying two-dimensional resistivity model are shown in Figure 3. The agreement between calculated apparent resistivities and observed data is good. About 20 trial-anderror iterations were required, however, to reach the model shown, even though the Inttial model was the final one developed in 1978 (FIg. 2). In general, the 1978 and 1979 models are very simflar, although in 1979 the dimension of the pseudosection was increased by $40 \%$. Additional measurement points were needed to provide coverage over the newly discovered eastern part of the fleld, and to obtain information to greater depths than the $1.5 \mathrm{~km}$ obtained in the 1978 survey.

Analysis of the differences in calculated apparent res1st1vity between 1978 and 1979 data sets Indicates that variations to as much as $25 \%$ exist between the two sets (Figs. 2 and 3 ). Most of this variation is probably due to inaccuracles in the 1978 data set since all deviations fall within the predicted scatter for those points (Wilt et al., 1979). Because of the large scatter, we made no attempt to interpret resistivity changes due to changing reservolr conditions. Standard error for the 1979 data is considerably lower than for 1978 data. However, errors for most data are less than $3 \%$ and for all data, less than $10 \%$.

A comparison of the bottom section of figures 2 and 3 show where the 1978 and 1979 resistivity models differ. The important differences include a redefinition of the resistive body within the production zone, a more accurate estimate of the resistivity of the deeper horizons, and some new information over the newer, eastern part of the fleld.

The newer data indicate that the resistive body, which we associate with the zone of intense hydrothermal alteration and the reservoir units, dips eastward by approximately 30 to 50 degrees, deepening in the region of new production east of the power plant; the dipole-dipole method is not, however, particularly sensitive to the dip of inclined bodies. The data also suggest that this zone is fairly extensive and exists as a flat-lylng horlzon in the eastern portion of the fleld. The western boundary of this unit lies about halfway between k1lometers 9 and 10, which corresponds to a point about $0.5 \mathrm{~km}$ west of well M-9. The bottom of this zone cannot be accurately fixed because of the insensitivity of the model to changes at great depth. For the same reason the position of the basement is not accurately determined; the data do suggest that the basement lies at least 3 and $4 \mathrm{~km}$ below the surface, respectively west and east of the power plant. The positions of the step faults shown in Figure 3 are poorly determined.

Adjacent to the resistive un1t (Fig. 2) 1s a thin eastward-dipping conductive body. 


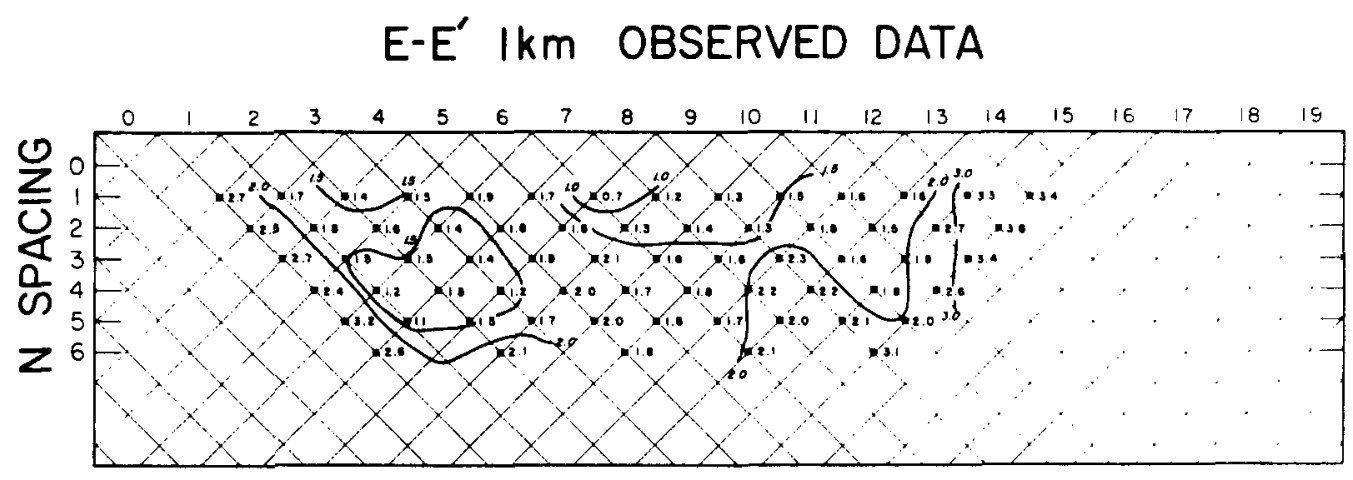

\section{E-E' $\mathrm{km}$ CALCULATED DATA}
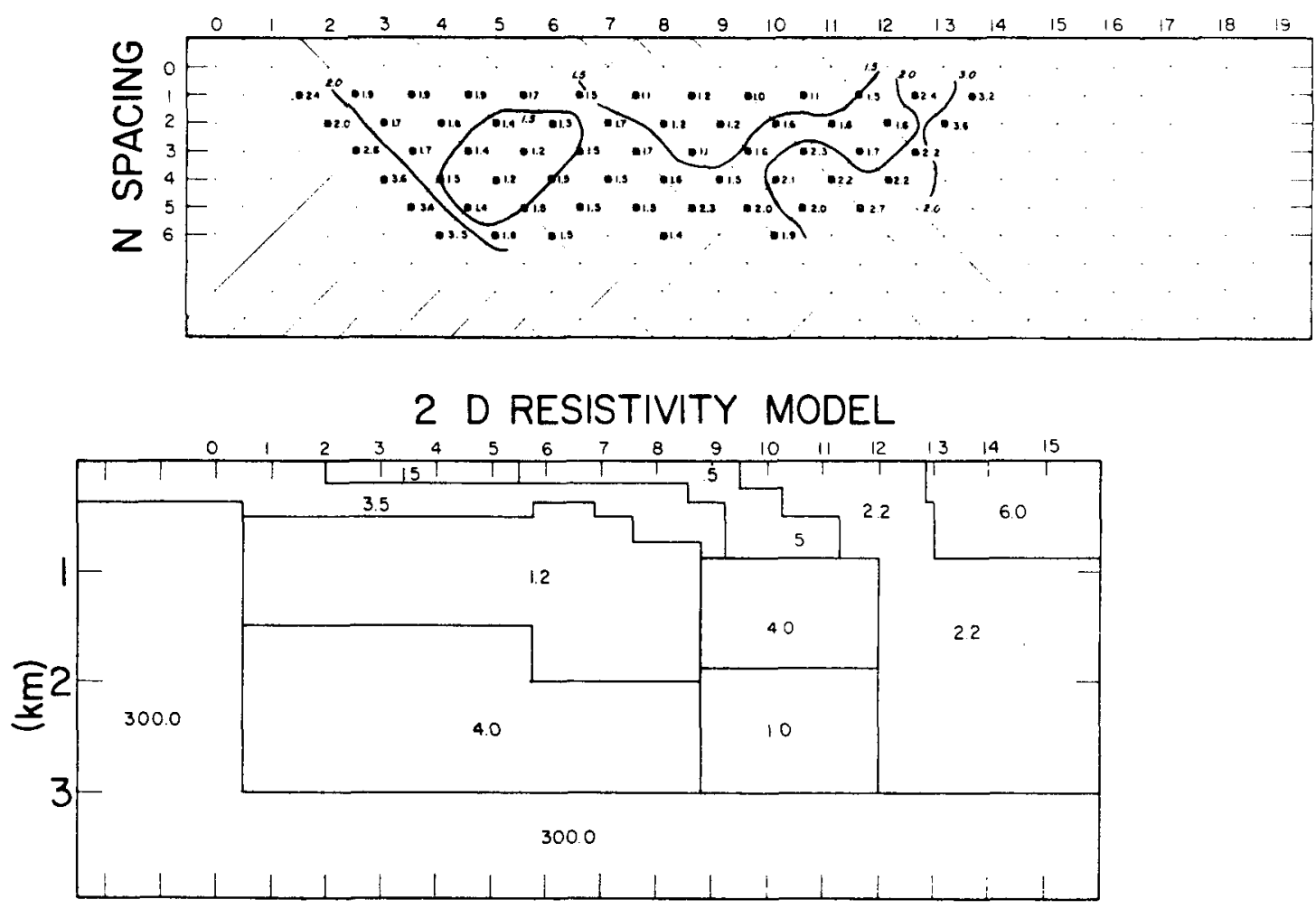

XBL $788-1635$

Figure 2. Mpole-dipole apparent resistivity pseudosection for 1-km dipoles along 11ne F-E', 1978; field data, model-generated data, and two-dimensional resistivity model.

This 1.5 ohm-m unit contrasts sharply with the 4.0 ohm-m body to the west and the 5.0 ohm-m body to the east. The body 18 approximately $1.5 \mathrm{~km}$ wide and dips eastward at between 30 and 50 degrees to a depth of between 2 and $2.5 \mathrm{~km}$; east of this it appears to be flat lying. Because the dipping portion of this unit corresponds remarkably with the location of the planes of charge proposed by Corwln (1979) on the basis of self-potential measurements, it possibly represents a zone of upward moving hot water that Ilnks the deeper eastern aquifers to the shallower production west of the power plant. If this assertion 18 correct, then changes associated with the deeper production in the east may be reflected in changes in the resistivity of this body. It would then be an excellent target for resistivity monitoring of changes in the newer production region. 
$E-E^{\prime} \mid \mathrm{km}$ OBSERVED DATA (1979)

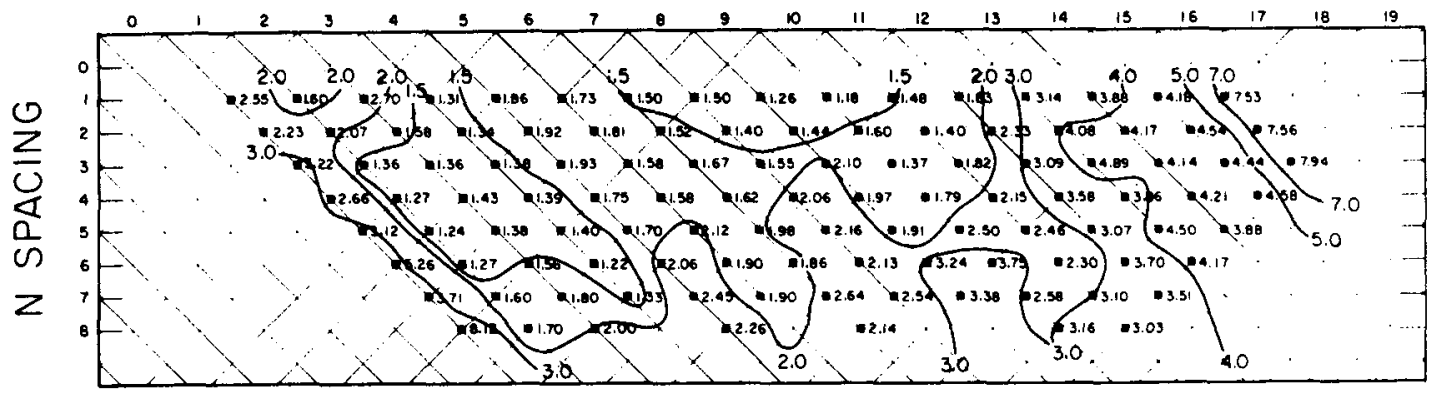

E-E' $1 \mathrm{~km}$ CALCULATED DATA

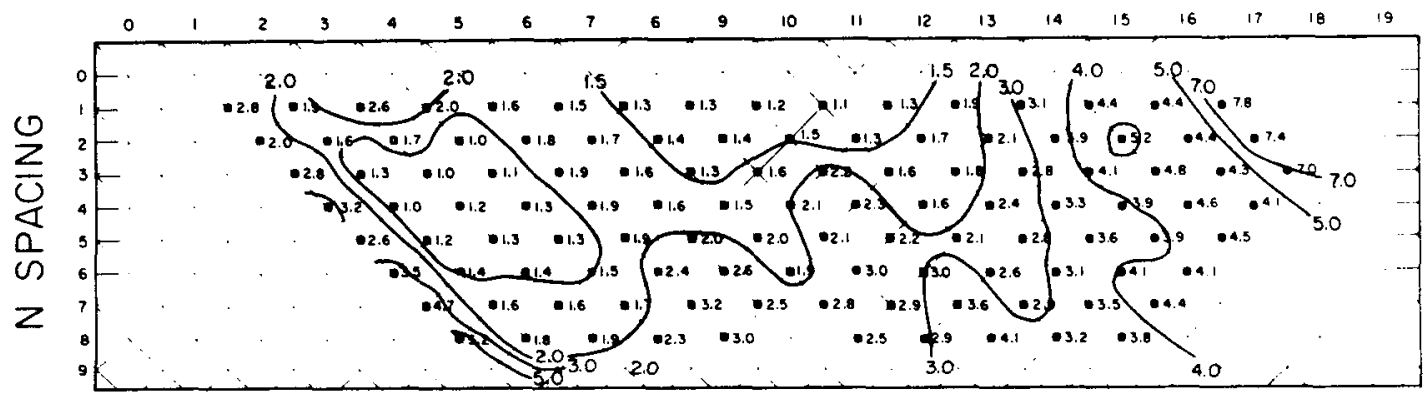

2 D RESISTIVITY MODEL

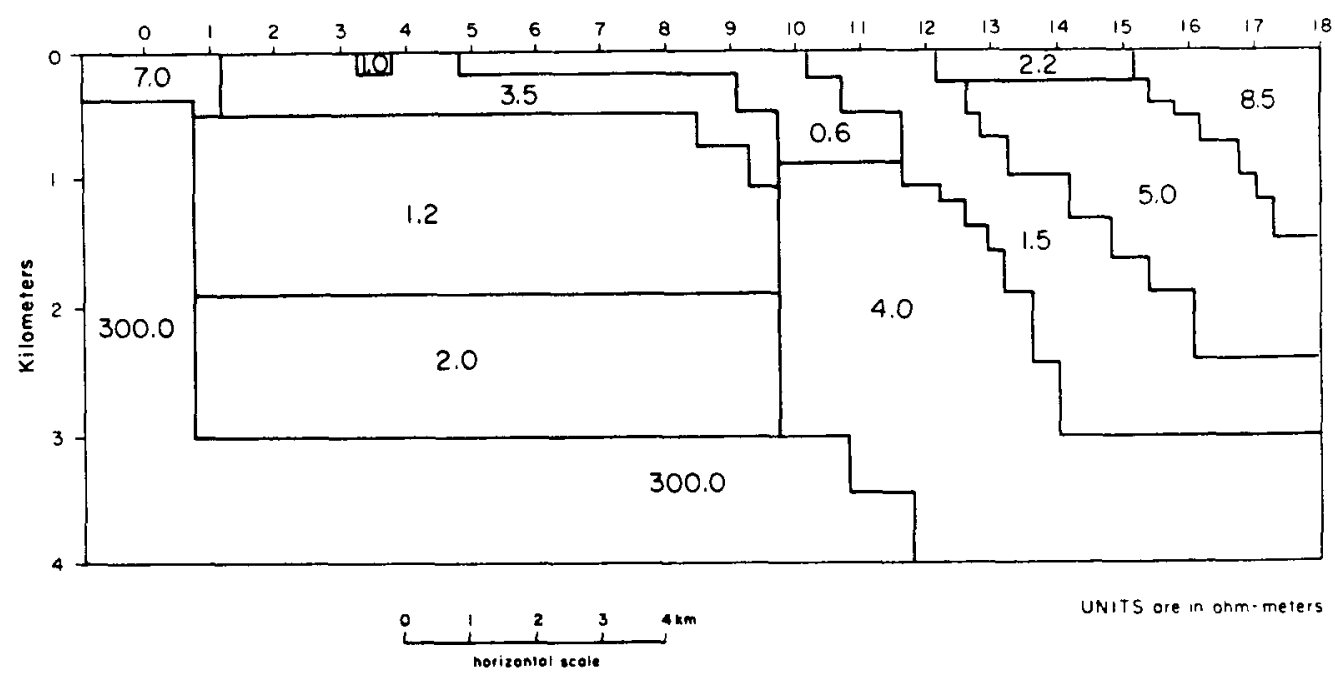

XBL $7910-13040 \mathrm{~A}$

Figure 3. Mpole-dipole apparent resistivity pseudosection for 1-km dipoles along 11ne F-E', 1979; fleld data, model-generated data, and two-dimensional resistivity model. 
Figure 3 also indicates that east of the power plant the rocks gradually become more resistive than the rocks west of the reservolr, by a factor of 5 . These rocks are shown as a series of blocks dipplng gently eastward to a depth of about $2 \mathrm{~km}$. The major cause of the increase in resistivity is the transition from brackish pore water to fresher water (Lyons and van de Kamp, 1980). The configuration of these unfts suggests a transition zone from deltaic waters to more saline sea waters (Lyons and van de Kamp, 1980).

\section{MODEL PERTURBATION STUDIES}

Figure 4 is an expansion of that portion of the resistivity section corresponding to the region of fluid production; for reference, some well locations are plotted. Dashed lines are plots of metamorphic mineral zonation (Lyons et al., 1980), the first occurrence of the metamorphic mineral epidote (Elders and Hoagland, 1979), and the boundary between unconsolidated and consolidated sediments in the wells (Puente C. and de la Peña L., 1979). The figure demonstrates the association between the abovementioned resistive body and the occurrence of high temperatures and metamorphic minerals in the production region. It also suggests that changes in the reservolr would be reflected in a relatively restricted part of the resistivity model, or that part assoclated with the reservoir and its recharge and discharge systems. Th1s limits the "region of interest" to about 60 observation points from the original 133. For these points future observations should be particularly important.

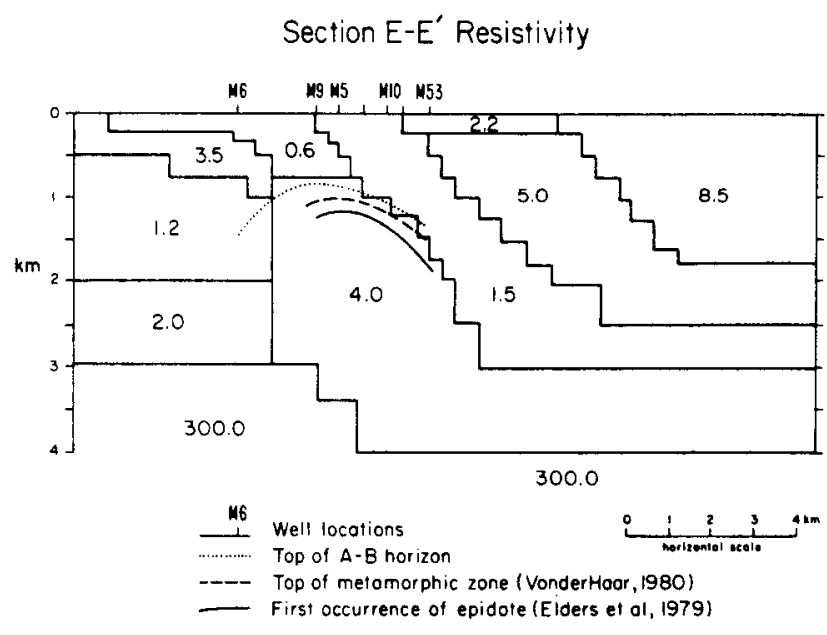

XBL $801-6761$

Figure 4. Expanded version of the two-dimensional resistivity model E-E'. Some well locations are plotted along the top of the figure and positions of varfous mineralogical and sedimentary horizons, as determined from well cuttings and $\log s$, are plotted below.
To study the effect of certain possible reservolr changes on the apparent resistivity of the 60 points, we have considered the effects from several perturbation models. From these model studies, three cases were selected corresponding to three scenarios of posstble reservoir changes (F1gs. 5 to 7 ). At the bottom of each model the percent deviation from the original model is calculated and plotted. Our ability to detect and interpret resistivity changes should then depend on our ability to analyze these plots.

\section{Case 1: Cold Water Intrusion}

Recent geochemical studies at Cerro Prieto have found that drawdown in some of the older producing wells is causing colder Colorado River water to move into the producing aquifer to replace produced fluid (Truesdell et al., 1979). Because the fresh river water is replacing more saline reservoir fluid, an increase in resistivity is expected in the producing region and in the rocks above $1 t$ and to the east.

Figure 4 simulates this change on a fairly large scale. The expansion of the 4 ohm-m zone represents the region that would contain fresher water because of the incursion and thus an increase in the resistivity by a factor of about 2.5. The changes in calculated apparent resistivity are fairly dramatic, up to $20 \%$, and they occur in banded regions. The predominance of high variations for the closer separations suggests that the source of the change is fairly shallow and the banded nature of the plot makes it difficult to confuse such changes with random measurement error. Some points in the plot actually decrease in apparent resistivity even though the only model changes were increases in resistivity. This presents a signature for such a model making 1 t easier to interpret apparent resistivity changes related to this type of reservolr change.

\section{Case 2: Discharge Zone Migration}

If the conductive $1.5 \mathrm{ohm}-\mathrm{m}$ zone shown in Figure 3 represents a region of upward flowing water, then changes in the resistivity of this zone can be expected as reservolr fluid 1s produced. One possible change from continuing production is the expansion of the 4.0 resistivity block eastward due to more mineral deposition and the inflow of lower salinity fluid and the subsequent eastward migration of the conductive region. If the conductive region represents a shear zone then this might correspond to an eastward migrating fault zone as the fluid moving through the shear zone deposits minerals and strengthens the rock matrix.

Figure 5 simulates such a case by shifting, the eastward boundary of the resistive zone and the adjacent conductive region eastward by $500 \mathrm{~m}$. Th1s model represents a falrly extensive change that might not be expected to occur over a short time interval, but the model is useful for showing 
Model Perturbation Case I-Cold Water Influx
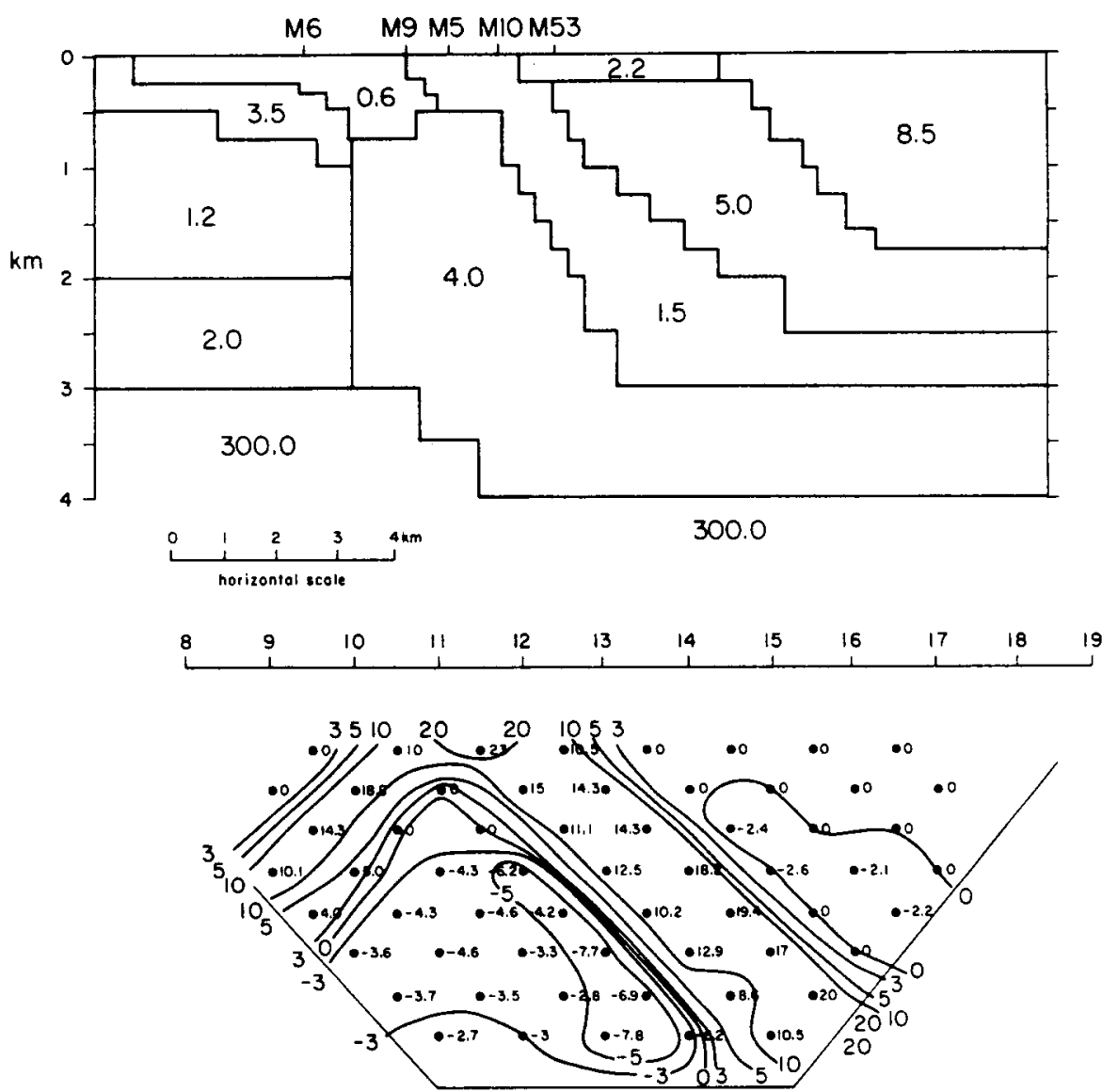

Percent variation

XBL $801-6759$

Figure 5. Model perturbation No. 1, corresponding to the resistivity change due to an influx of colder water into the shallower part of the system.

the effect of resistivity changes along thin inear fractures and establishing a pattern for such bodles. The percent varlation of apparent resistivity ranges to $15 \%$ and maximum values occur in easternmost located points.

\section{Case 3: Steam Zone Formation}

This case simulates the formation of a thin shallow steam zone in the upper part of the reservolr. Formation of such a zone follows from the observation that most of the wells near the power plant now produce a two-phase watersteam mixture, whereas the flutd originally produced was completely liquid (Truesdell et al., 1979). As this process continues the effect might be to reduce permeability because of local bolling and mineral deposition and to deplete the liquid water in the upper parts of the reservolr.

In Figure 6 this situation is simulated by increasing the resistivity by a factor of 2 for a 100-m-thick zone located at the top of the producing region. This represents a relatively minor change in reservoir conditions, but one that might occur over a short time interval.

The plot of percent variation (Figure 6) shows a maximum of $5 \%$ deviation due to the model perturbation. These relatively small changes in apparent resistivity should be difficult to observe but they do occur at shallow separations when data accuracy is greatest and they are 8 rouped so it would be easier to separate them from random measurement error. 


\section{Model Perturbation Case 2}
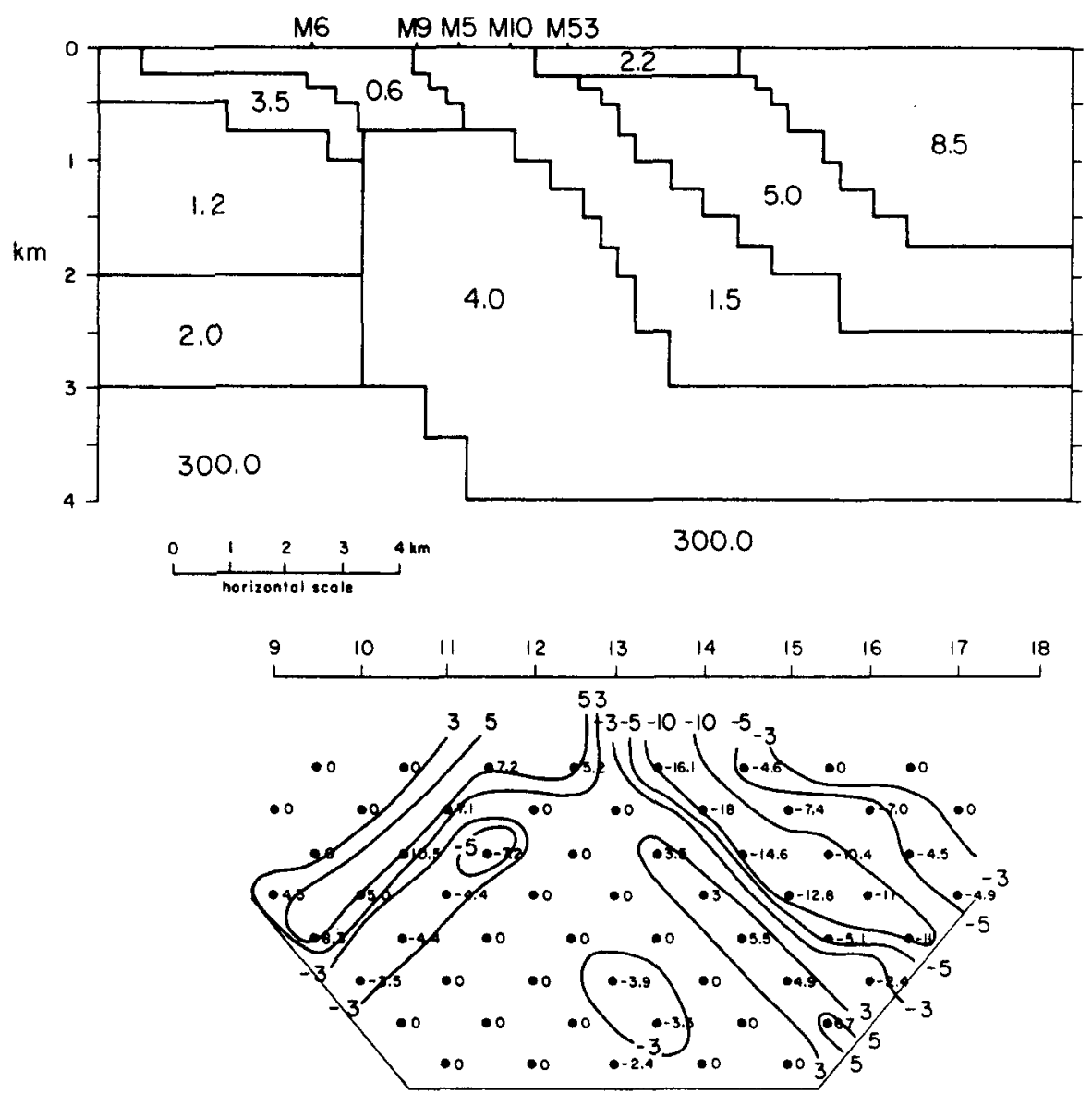

Percent variotion

XBL $801-6758$

Figure 6. Model perturbation No. 2, corresponding to the expansion of the 4 ohm-m zone eastward due to reduced temperature and secondary mineral precipitation.

\section{TELLURIC PROFILE RESULTS}

A 12-station tellurfc profile survey was measured along line $E-E^{\prime}$ in an attempt to delineate subsurface structure and to assess the usefulness of this reconnalssance method in resistivity monitoring.

The basis of the technique is the simultaneous measurement of natural electrical fields in two or more adjacent segments of a survey line and analysis of the differences in observed amplitude and phase of the Incoming signal. Because the source of these signals 18 the same, analysis of differences is useful for interpreting differences in geology beneath the measurement points. For a more complete discussion see Yungul et al., 1973.

Figure 7 shows a plot of the amplitude and phase ratios for survey line E-E'. The E-E' stations correspond to the same ones used for the dipole-dipole pseudosections (Fig. 3). The telluric signals were recorded at a period of $25 \mathrm{sec}$, which corresponds to a waximum depth of Investigation of about $3 \mathrm{~km}$; longer period signals would penetrate deeper, and shorter periods not as deep. The profile then gives a running ratio of the bulk resistivities beneath the line. The method is especially useful in detecting lateral resistivity contrasts since these form barrlers to natural horfzontal current flow. For this reason and because of the simplicity of this method 1 t was chosen to be tested at Cerro Prieto.

A sample record for station 7 of line $E-E^{\prime}$ is shown in Figure 8. The amplitude and phase polnts are determined from the scattergram and vector plots by selecting the value that corresponds to the outermost cluster of the plotted observed values. This procedure is 


\section{Model Perturbation Case 3-Thin Steam Cap}
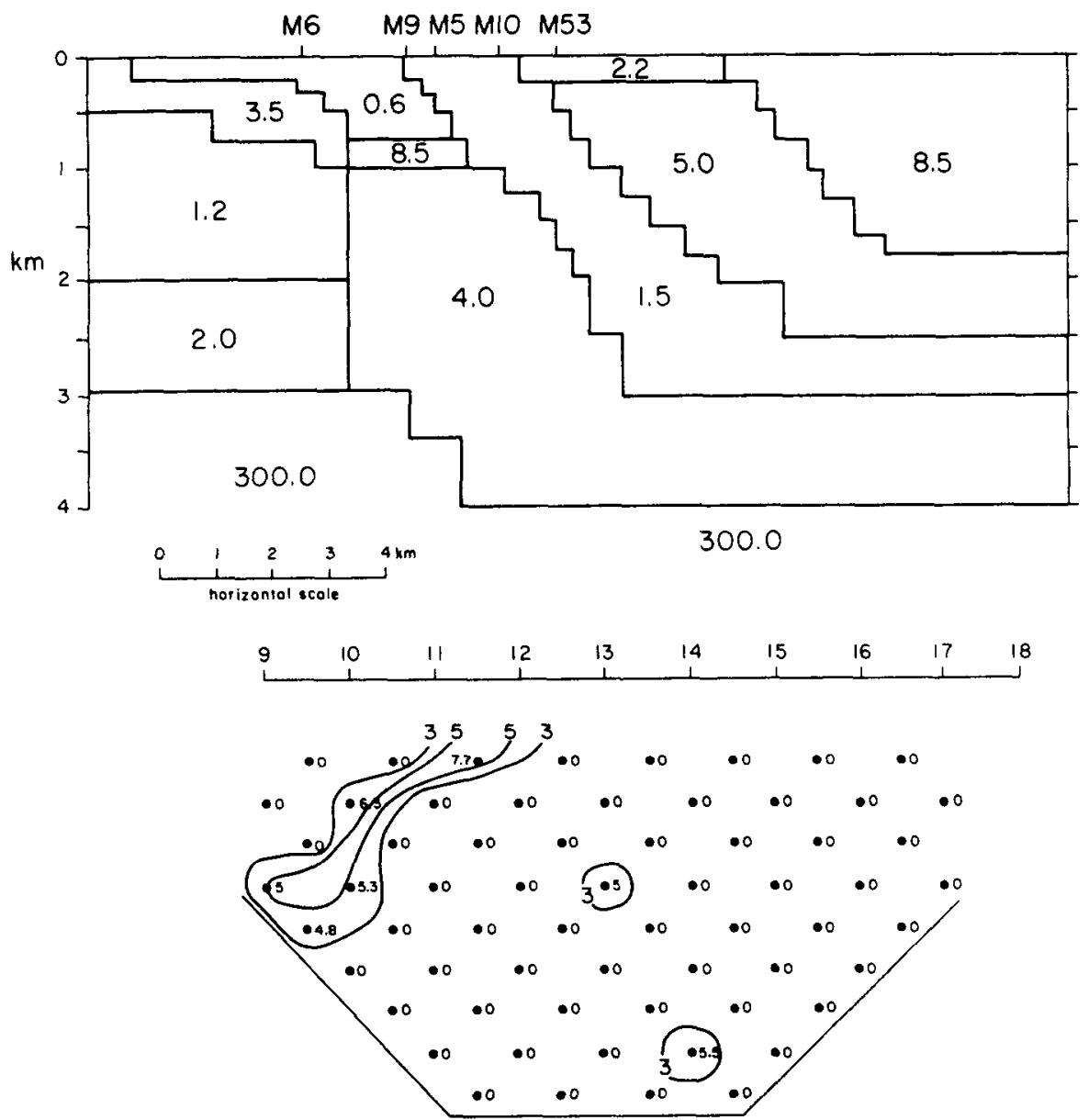

Percent variotion

XBL $801-6760$

Figure 7. Model perturbation No. 3, corresponding to the formetion of a shallow steam zone.

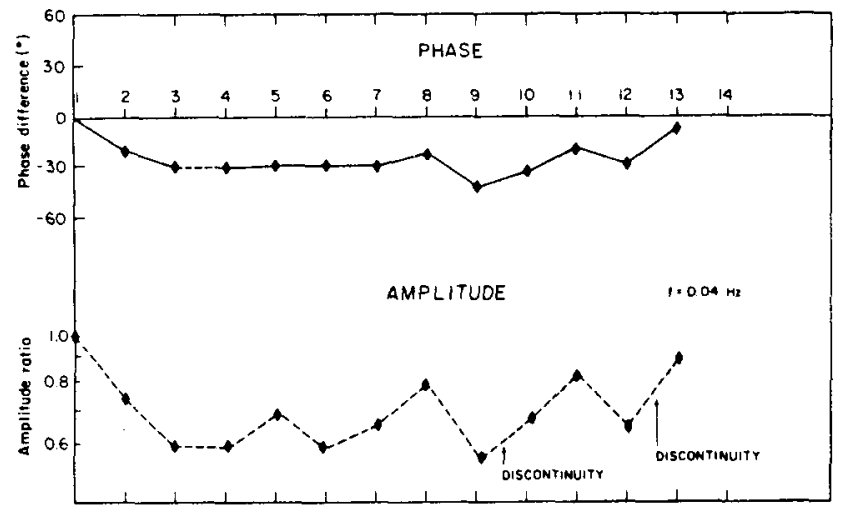

XBL $\quad 7910-13020$

Figure 8. Plot of amplitude and phase ratios from telluric profile plot E-E'. followed because a two-dimensional earth energized by electric fields in all directions will yield telluric amplitude ratios with a bimodal distribution; ratios near 1 correspond to geologic strike and the farthest cluster of points correspond to the direction perpendicular to strike. Since the profile was inclined approximately perpendicular to strike, we chose values corresponding to that polarization.

An analysis of Figure 8 reveals a problem inherent to this method that limits its value where high accuracy is needed. Even in the absence of notse there is a natural scatter because of random fleld polarization. This Introduces error into the estimation of ratios. This error may be significantly larger than the precision necessary for accurate monitoring. Another problem with this method is that the depth to the source of perturbations is difficult 
to determine because the measurement is done at only one frequency.

An analysis of Figure 9 reveals some of the features of the Cerro Prieto field detectable with telluric profile measurements. The steep decline in the first several measurements Indicates the effect of the Cucapa range (located $2 \mathrm{~km}$ west of station 1) first. A discontinuity is evident between stations 9 and 10 . This corresponds to the western boundary of the geothermal field and correlates well with the location determined from a detalled interpretation of dipole-dipole results. The problem with measurements taken with $1-\mathrm{km}$ dipoles, however, is that the resolution of lateral features is no better than the dipole length. Therefore, it is 1mpossible to tell exactly where discontinulties occur unless the dipoles are made sma1l. Another discontinulty is evident between stations 12 and 13 . This correlates well with the area of steep decline of the resistive body interpreted with dipole-dipole data and may relate to a zone of faulting.

\section{TELLURIC DATA LINE E-E' STATION 7}

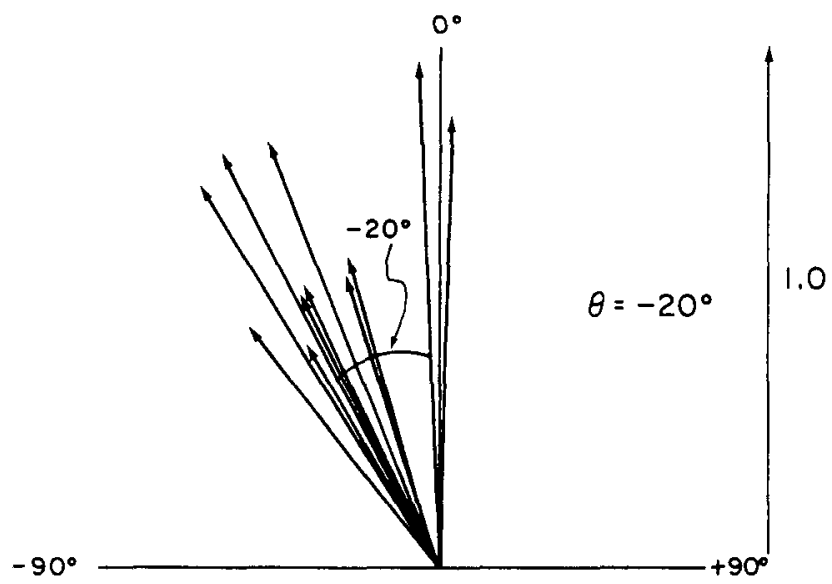

(a) RELATIVE PHASE

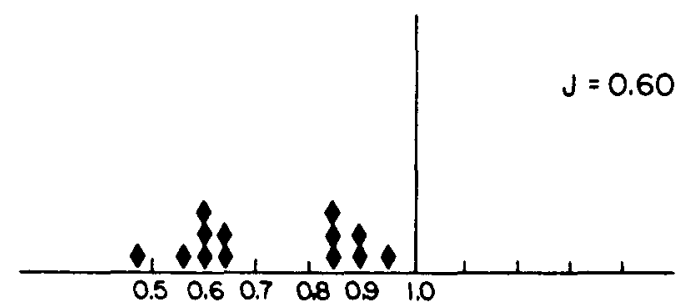

(b) RELATIVE AMPLITUDE

XBL $7910-13021$

Figure 9. Scattergram and vector plot from a typical telluric profile station. plotted points correspond to Individual measurements.
The telluric measurements suggest a slight Increase and resistivity over the reservoir region, but since several faults are crossed by the widely spaced stations the lateral effects cannot be totally separated from the vertical. In general the phase changes closely follow the amplitude changes giving more creedence to the interpretation but not supplying any new information.

Since the profile was measured in two days by two people and very little equipment was necessary, the amount of reconnaissance information obtainable is significant. It does not seem Ilkely, however, that this method is well sulted for resistivity monitoring.

\section{CONCLUSIONS}

The following is a summary of some of our find lings :

1. The dipole-dipole data-gathering technique was improved in 1979 to where estimated measurement errors are less than $3 \%$ for most points. This is sufficient accuracy to observe small scale changes in resistivity that may occur over short time intervals.

2. Resistivity modeling of the expanded 1979 profile has better defined the resistivity structure of the eastern part of the field. The models suggest that the resistive body associated with the producing zone dips eastward at 30 to 50 degrees to a depth of greater than $2.0 \mathrm{~km}$. A narrow, steeply dipping conductive zone lies immediately east of the resistive body and may be associated with a zone of recharge or faulting.

3. The resistivity modeling suggests a deep source of fluld in the eastern part of the field. There is also some evidence of a connection between the older, shallower and the newer, deeper production.

4. Model perturbation studies show that apparent resistivity changes due to model vartations normally run as banded or grouped areas of anomalous apparent resistivities. The signature of such models may allow detection and Identification of changes in the presence of nolse. The study also helped define an "area of Interest" of 60 measurement points particularly associated with changes in the reservolr formation.

5. Interpretation of telluric profile measurements done over line $E-E^{\prime}$ ylelds a significant amount of reconnalssance information about the fleld. Because of inherent measurement uncertainty however, the method seems unsultable for monttoring purposes.

\section{ACKNOWLEDGMENTS}

Work performed for the U. S. Department of Energy, Division of Geothermal Energy, under contract W-7405-ENG-48. 
REFERENCES CITED

Corwin, R. F., Morrison, H. F., Diaz C., S., and Rodrfiguez B., J., 1979, Self potential studies at the Cerro Prleto geothermal field, in Proceedings, First Symposium on the Cerro Prieto Geothermal Fleld, Baja California, Mexico, September 1978: Berkeley, Lawrence Berkeley Laboratory, LBL-7098, p. 204-210.

Elders, W. A., and Hoagland, J. R., 1979, Studles of water/rock interaction in the Cerro Prieto geothermal fleld, Baja California, Mexico, in Abstracts, Second Symposium on the Cerro Prieto Geothermal Field Baja California, Mexico: Mexical1, Comisión Federal de Electrictdad.

Lyons, D. J., and van de Ramp, P. C., 1980, Subsurface geological and geophysical study of the Cerro Prieto geothermal field: Berkeley, Lawrence Berkeley Laboratory, LBL-10540 (1n press).

Lyons, D. J., van de Ramp, P. C., Vonder Haar, S., Noble, J., and Howard, J. H., 1980, Subsurface stratigraphy at the Cerro Prieto geothermal field, in Second Symposium on the Cerro Prieto Geothermal Field, Baja
California, Mexico: Mexical1, Comistón Federal de Electricidad (this volume).

Puente C., I., and de la Peña L., A., 1979, Geologfa del campo geotérmico de Cerro Prieto, in Proceedings, First Symposium on the Cerro Prleto Geothermal Field, Baja California, Mexico, September 1978: Berkeley, Lawrence Berkeley Laboratory, LBL-7098, p. $17-40$.

Truesdell, A. H., Nehr1ng, N. L., Thompson, J. M., Coplen, T. B., DesMaris, D. J., Jan1k, C. J. and Mehl, D. C., 1979, Geochemical studies of the Cerro Prleto reservolr fluld, in Abstracts, Second Symposium on the Cerro Prieto Geothermal Field, Baja California, Mexico: Mexicali, Comisión Federal de Electricid ad.

Wilt, M. J., Goldstein, N. E., and Razo M., A., 1979, LBL Resistivity studies at Cerro Prieto, In Proceedings, First Symposium on the Cerro Prieto Geothermal Fleld, Baja Calffornia, Mexico, September 1978: Berkeley, Lawrence Berkeley Laboratory, LBL-7098, p. 179-188.

Yungul, S. H., Hembree, M. R., and Greenhouse, J. P., 1973, Tellurtc anomalies associated with 1solated reefs in the midland basins, Texas: Geophysics, v. 38, p. 545-556. 
This report was done with support from the Department of Energy. Any conclusions or opinions expressed in this report represent solely those of the author(s) and not necessarily those of The Regents of the University of California, the Lawrence Berkeley Laboratory or the Department of Energy.

Reference to a company or product name does not imply approval or recommendation of the product by the University of California or the U.S. Department of Energy to the exclusion of others that may be suitable. 
TECHNICAL INFORMATION DEPARTMENT

LAWRENCE BERKELEY LABORATORY

UNIVERSITY OF CALIFORNIA

BERKELEY, CALIFORNIA 94720 